East African Medical Journal Vol. 80 No. 9 September 2003 CHRONIC MYELOID LEUKAEMIA IN CENTRAL AFRICANS

J.M. Mukiibi, BSc, MBChB, MMed Path (Haemat), FRCP (Edin.), Professor and Head, Department of Haematology, C.M. Nyirenda, MD, DTM \& H, MMed (Med), Chief Physician and Clinical Senior Lecturer, Department of Medicine, University of Malawi, College of Medicine, Private Bag 360, Chichiri, Blantyre 3, Malawi, B. Paul, FRC Path, Senior Consultant Haematologist, BassetLaw Hospital (Formely Senior lecturer. Department of Haematology, University of Zimbambwe, Medical School, J.O. Adewuyi, MBBS, DCP, FMC Path, FWACP, Professor and Head, Department of Haematology, University of Zimbabwe, Medical School, P.O. Box A 178, Avondale, Harare, Zimbabwe, E.L.B. Mzula, DMLT (Haemat and BTS), Chief Laboratory Technologist and H.N. Malata, DMLT, Senior Laboratory Technologist, Department of Haematology, University of Malawi, College of Medicine, Private Bag 360, Chichiri, Blantyre 3, Malawi

Request for reprints to: Professor J.M. Mukiibi, Department of Haematology, College of Medicine, University of Malawi, Private Bag 360, Chichiri, Blantyre 3, Malawi

\title{
ABSTRACT
}

\section{CHRONIC MYELOID LEUKAEMIA IN CENTRAL AFRICANS}

\author{
J.M. MUKIIBI, C.M. NYIRENDA, B. PAUL, J.O. ADEWUYI, E.L.B. MZULA, and H.N. MALATA
}

\begin{abstract}
Objectives: To document the pattern of presenting clinical and haematological features of chronic myeloid leukaemia (CML) in central Africans and evaluate the clinical consequences of treating the disease with chemotherapy.

Design: Prospective descriptive analysis of clinical and haematological data.

Setting: Departments of Haematology of tertiary referral centres and teaching hospitals.

Materials and Methods: Prospective clinical and haematological data were collected on 150 central Africans ( 90 Zimbabweans and 60 Malawians) using modern Coulter counters and standard up-to-date haematological procedures and the results analysed using predetermined criteria and the top-desk Scientific Calculator Model HP 48GX, Texas Instruments, USA. Results: There were $150 \mathrm{CML}$ patients studied. Males predominated in a ratio of 1:5:1. The youngest patient was 10 years and the oldest 77 years with a mean \pm s.d. of $38.9 \pm 14.7$ years. The peak age incidence of $47.3 \%$ occurred between 21 to 40 years. The Ph chromosome was found in 19 of the 20 patients studied. Although complaints attributed to splenic enlargement were the most common symptoms, several unusual clinical features were encountered viz: hepatomegaly (26\%), bleeding (12\%), significant Iymphadenopathy $(11.3 \%)$, purpura (3.3\%), skin infiltration (2.7\%), cardiac failure $(2.7 \%)$ and $14.7 \%$ were diagnosed incidentally. Symptoms such as fatigue, headaches and weight loss were associated with greater degrees of leucocytosis, severe to gross splenomegaly and lower haemoglobin levels. The severe to gross splenomegaly which occurred in $68(45.3 \%$ ) suggests that patients in this part of the world seek medical advice rather late in the disease. The median survival times of 65,47 and 39 months respectively for alpha interferon, hydroxyurea and busulphan are in agreement with those of previous larger series from other parts of the world.

Conclusions: The study has revealed that the presenting pattern of clinical and haematological features of CML is changing probably due to the advent of modern clinical practice coupled with increased physician density, greater awareness of disease among clinicians besides other reasons. However, optimal treatment is not possible for the majority of patients due to lack of chemotherapeutic agents and supportive care.

Recommendation: Referral centres in African health systems should be equipped for better management of CML patients.
\end{abstract}

\section{INTRODUCTION}

There is ample documentation for the occurrence of chronic myeloid leukaemia (CML) in indigenous Africans (1). Besides, until recently, the majority of patients with CML have presented with insidious onset of symptoms and signs attributable to splenomegaly, anaemia and hypermetabolism with only very occasional patients being diagnosed incidentally; regardless of the country's level of development. However, recent literature from developed western countries (2-4) has disclosed that unusual clinical features such as: bleeding, thrombosis, arthralgia, leukaemic cutis, spinal cord compression, peptic ulceration or priapism are commoner presentations today than what was observed or published decades ago. Furthermore, with the current medical practice which is readily accessible in the western hemisphere, CML has been diagnosed in 10 to $50 \%$ of patients before the onset of symptoms as a result of blood tests on apparently healthy persons for pregnancy, before blood donation or medical insurance examinations or in the course of investigations for unrelated disoders (2$4)$. With gradual introduction of modern practice to developing countries particularly in sub-Saharan Africa, it was felt necessary to conduct a study first to determine the pattern of presenting clinical and haematological features of CML in central Africans and secondly to evaluate the clinical consequences of treating the disease with chemotherapy. 


\section{MATERIALS AND METHODS}

The study comprised 90 Zimbabweans and 60 Malawians who were consecutively seen and prospectively documented by the authors at the Departments of Haematology of the University of Zimbabwe, Medical School, Harare, Zimbabwe, from January 1985 to December 1991 and the University of Malawi, College of Medicine, Blantyre, Malawi, between January 1992 and December 2002 respectively. For each patient, clinical details were recorded after a history and a physical examination had been done. In Harare, full blood counts (Fbcs) were analysed using Coulter Counter Models S and JS and in Blantyre Fbcs were determined using Coulter Counter Onyx. Other relevant tests done included: bone marrow aspirations and/or trephine biopsies, neutrophil alkaline phosphatase (NAP), reticulocyte count, cytogenetic studies (done only in 20 patients mostly in South Africa) and in some cases biochemistry profiles whenever these were indicated. All haematological tests were carried out according to standard techniques (5).

Criteria for inclusion in the study: All patients who were diagnosed to have CML either in the chronic or advanced phases of the disease. Patients were considered to be in advanced phase of the disease if they had: myelofibrosis, blasts $>15 \%$ or cytogenetic abnormalities in addition to the $\mathrm{Ph}$ chromosome. Anaemia was diagnosed if the haemoglobin $(\mathrm{Hb})$ concentration was $<13 \mathrm{~g} / \mathrm{dl}$ in males and $<11 \mathrm{~g} / \mathrm{dl}$ in females. Thrombocytosis was deemed to be present if the platelet count was $\geq 450 \times 10^{\circ} \mathrm{L}$ and thrombocytopenia was defined as a platelet count of $<150 \mathrm{x}$ $10^{\circ} \mathrm{L}$. After initial investigations, patients were seen at fortnightly to one monthly intervals at the clinics. Chemotherapy was used for only a few patients who could afford to buy the drugs on their own account. Of the $24(16 \%)$ patients who could afford to procure drugs on their own accounts, six received alpha-interferon, eight received hydroxyurea and 10 received busulphan.

The treatment schedules were: (i) Inj. alpha-interferon 3 $\mathrm{Mu} / \mathrm{m}^{2}$ subcutaneously (s-c) daily initially with gradual increases up to $5 \mathrm{Mu} / \mathrm{m}^{2} \mathrm{~s}$-c daily; (ii) Cap. hydroxyurea $2 \mathrm{~g}$ orally daily initially reducing to maintenance dose of 1.0 to $1.5 \mathrm{~g}$ orally daily; (iii) Tab busulphan 6 to $8 \mathrm{mgs}$ orally daily reducing to maintenance dose of 1 to $2 \mathrm{mgs}$ orally daily. In all cases white cell count was monitored closely and drug dosage adjusted till counts were between 20 and $30 \times 10^{\circ} \mathrm{L}$ when the drugs were either stopped or reduced to maintenance doses. Tab Allopurinol 100 to $300 \mathrm{mgs}$ orally daily was also administered during each course of cytotoxic therapy as prophylaxis for hyperuricaemia. The majority of 126 (84\%) patients could not afford chemotherapy and were therefore treated conservatively. The Student's t-test and Chi-squared tests were used to determine the statistical significance between groups. P-value of less than 0.05 was considered significant.

\section{RESULTS}

Of the 150 patients studied $128(85.3 \%)$ presented in the chronic phase and $22(14.7 \%)$ were in advanced phase. Male patients out numbered females with a ratio of 1.5:1. The overall mean \pm s.d. age was $38.9 \pm 14.7$ years (range 10 - 77 years). The peak age incidence occurred in the 3rd and 4 th decades and the mean \pm s.d. duration of symptoms recorded in 95 patients was $1.9 \pm 1.8$ months (range 0-12 months). The characteristics of the 150 patients are summarised in Table 1.

Table 1

Characterstics of 150 patients with CML

\begin{tabular}{|c|c|c|}
\hline Characteristic & No. $(n=150)$ & $\%$ \\
\hline \multicolumn{3}{|l|}{ Period of diagnosis: Nationality } \\
\hline Jan 1985 - Dec 1991: Zimbabwean & 90 & 60.0 \\
\hline Jan 1992 - Dec 2002: Malawian & 60 & 40.0 \\
\hline \multicolumn{3}{|l|}{ Age (years) } \\
\hline $0-20$ & 13 & 8.7 \\
\hline $21-40$ & 71 & 47.3 \\
\hline $41-60$ & 52 & 34.7 \\
\hline$>60$ & 14 & 9.3 \\
\hline \multicolumn{3}{|l|}{ Sex } \\
\hline Male & 90 & 60.0 \\
\hline Female & 60 & 40.0 \\
\hline \multicolumn{3}{|l|}{ Disease phase } \\
\hline Chronic & 128 & 85.3 \\
\hline Advanced* & 22 & 14.7 \\
\hline \multicolumn{3}{|l|}{$\mathrm{Ph}$ chromosome** } \\
\hline Total No. tested & 20 & 100.0 \\
\hline Present & 19 & 95.0 \\
\hline Absent & 1 & 5.0 \\
\hline \multicolumn{3}{|l|}{ Duration of Symptoms (months)** } \\
\hline No. of patients with positive information & 95 & 100.0 \\
\hline $0-1.5$ & 57 & 60.0 \\
\hline $1.6-3.0$ & 27 & 28.4 \\
\hline$>3$ & 11 & 11.6 \\
\hline
\end{tabular}

\footnotetext{
* Presence of bone marrow blasts $>15 \%$, myelofibrosis, or other cytogenetic abnormalities in addition to Ph chromosome
}

** Incomplete data; to calculate percentage, denominator = number for which information was available 
Symptoms and signs: These are given in Table 2. Complaints attributable to splenic enlargement were the most common symptoms followed by fatigue or lethargy, headache and weight loss.
Notable clinical features included: hepatomegaly (26\%) bleeding (12\%) lymphadenopathy $(11.3 \%)$, purpura (3.3\%), skin inflitration (2.7\%) and as incidental diagnosis in $14.7 \%$ of the patients

Table 2

Clinical features at diagnosis in 150 patients with CML

\begin{tabular}{|c|c|c|}
\hline Clinical feature & No. $(n=150)$ & $\%$ \\
\hline \multicolumn{3}{|l|}{ Symptoms } \\
\hline Splenic discomfort & 85 & 56.7 \\
\hline Abdominal fullness or mass & 61 & 40.7 \\
\hline Fatigue or lethargy & 45 & 30.0 \\
\hline Headache & 27 & 18.0 \\
\hline Weight loss & 26 & 17.3 \\
\hline Weakness & 23 & 15.3 \\
\hline Malaise & 19 & 12.7 \\
\hline Bleeding from nose, gums and other sites & 18 & 12.0 \\
\hline Dizziness & 15 & 10.0 \\
\hline Bone pains & 5 & 3.3 \\
\hline Palpitations & 5 & 3.3 \\
\hline Excessive sweating & 4 & 2.7 \\
\hline Dyspnoea & 3 & 2.0 \\
\hline Visual disturbance & 3 & 2.0 \\
\hline Infections & 2 & 1.3 \\
\hline Others* & 3 & 2.0 \\
\hline \multicolumn{3}{|l|}{ Signs } \\
\hline Spleen palpable & 130 & 86.7 \\
\hline $1-9.9 \mathrm{cms}$ (Mild to moderate splenomegaly) & 62 & 41.3 \\
\hline $10-19.9 \mathrm{cms}$ (Severe splenomegaly) & 48 & 32.0 \\
\hline$\geq 20 \mathrm{cms}$ (Gross splenomegaly) & 20 & 13.3 \\
\hline$\overline{\text { Spleen not palpable }}$ & 20 & 13.3 \\
\hline Anaemia & 63 & 42.0 \\
\hline Palpable liver & 39 & 26.0 \\
\hline Lymphadenopathy & 17 & 11.3 \\
\hline Purpura & 5 & 3.3 \\
\hline Leukaemic skin infiltration & 4 & 2.7 \\
\hline Oedema & 4 & 2.7 \\
\hline Pyrexia & 4 & 2.7 \\
\hline Cardiac failure & 4 & 2.7 \\
\hline Ascites & 1 & 0.7 \\
\hline Incidental diagnosis & 22 & 14.7 \\
\hline
\end{tabular}

* Others included: fever, cough, priapism in one patient each

Haematological features at diagnosis: These were not statistically different between the Zimbabwean and Malawian groups. Marked leucocytosis (wbc count $\geq 100$ x $10^{\circ} \mathrm{L}$ found in 119 (79.3\%) patients), moderate to severe anaemia $(\mathrm{Hb} \leq 9.4 \mathrm{~g} / \mathrm{dl}$ recorded in $86(57.3 \%)$ patients and thrombocytosis (Platelet count $>450 \times 10^{9} \mathrm{~L}$ detected in 63 (42\%) patients), were common features (Table 3 ). NAP activity was low in the 90 patients in which it was studied and the scores ranged from 0 to 19 with a mean \pm s.d. value of $4.9 \pm 4.1$. 
Table 3

Haematological findings at diagnosis in 150 patients with CML

\begin{tabular}{|c|c|c|c|c|}
\hline Blood count index & No. & $\%$ & Mean \pm s.d & Range \\
\hline $\mathrm{Wbc}\left(\mathrm{x10} 0^{9} / \mathrm{L}\right)$ & 150 & 100.0 & $223.7 \pm 159.5$ & $15.4-998.0$ \\
\hline $\mathrm{Hb}(\mathrm{g} / \mathrm{dL}) 150$ & 150 & 100.0 & $8.9 \pm 2.3$ & $3.7-14.7$ \\
\hline Platelets (x109/L) & 150 & 100.0 & $443.0 \pm 306.8$ & $38.0-1783.0$ \\
\hline \multicolumn{5}{|l|}{$\mathrm{Wbc}\left(\mathrm{x} 10^{9} / \mathrm{L}\right)$} \\
\hline$<20$ & 10 & 6.7 & $17.7 \pm 1.5$ & $15.4-19.6$ \\
\hline $20-99$ & 21 & 14.0 & $77.9 \pm 17.4$ & $46.0-98.9$ \\
\hline $100-249$ & 75 & 50.0 & $183.5 \pm 39.7$ & $103.0-248.0$ \\
\hline $250-349$ & 20 & 13.3 & $290.2 \pm 36.1$ & $250.0-349.0$ \\
\hline$\geq 350$ & 24 & 16.0 & $507.0 \pm 166.5$ & $350.0-998.0$ \\
\hline \multicolumn{5}{|l|}{$\mathrm{Hb}(\mathrm{g} / \mathrm{dL})$} \\
\hline$\leq 7.4$ & 42 & 28.0 & $6.2 \pm 1.0$ & $3.7-7.3$ \\
\hline $7.5-9.4$ & 44 & 29.3 & $8.3 \pm 0.5$ & $7.5-9.3$ \\
\hline $9.5-10.9$ & 36 & 24.0 & $10.3 \pm 0.4$ & $9.6-10.9$ \\
\hline$\geq 11.0$ & 28 & 18.7 & $12.0 \pm 1.0$ & $11.0-14.7$ \\
\hline \multicolumn{5}{|l|}{ Platelets $\left(\times 10^{9} / \mathrm{L}\right)$} \\
\hline$<50$ & 6 & 4.0 & $44.7 \pm 4.6$ & $38.0-49.0$ \\
\hline $50-149$ & 15 & 10.0 & $115.5 \pm 2.8$ & $65.0-146.0$ \\
\hline $150-449$ & 66 & 44.0 & $301.5 \pm 79.3$ & $157.0-449.0$ \\
\hline $450-599$ & 28 & 18.7 & $508.0 \pm 50.1$ & $450.0-589.0$ \\
\hline$\geq 600$ & 35 & 23.3 & $866.5 \pm 309.4$ & $608.0-1783.0$ \\
\hline \multicolumn{5}{|c|}{ NAP score* $(n=90)$} \\
\hline$<5$ & 48 & 53.3 & $1.9 \pm 1.6$ & $0-4$ \\
\hline $5-10$ & 32 & 35.6 & $6.9 \pm 1.5$ & $5-10$ \\
\hline$>10$ & 10 & 11.1 & $13.1 \pm 2.5$ & $11-19$ \\
\hline
\end{tabular}

* Neutrophil Alkaline Phosphatase score: Incomplete data: to calculate percentage, denominator = number for which information was available

Bone Marrow findings: The bone marrow aspiration done in 97 (64.7\%) of the patients showed a consistent pattern of marked to gross granulocytic and megakaryocytic hyperplasia with a spectrum of maturation in the myeloid line. The trephine biopsy done only in $45(30 \%)$ patients showed frank myelofibrosis in two (4.4\%) of the patients in which the procedure was done and no granulomas or other abnormalities were detected.

Response to chemotherapy and survival data: Only $24(16 \%)$ out of 150 patients could afford to procure drugs on their own account and were therefore the ones available for evaluation. The majority of patients, 126 (84\%), who could not afford the drugs were conservatively treated and most of them were lost to follow up within four to ten weeks of diagnosis. For the 24 patients treated with cytotoxic drugs, the results of treatment and survival duration are given in Table 4.

Table 4

Treatment with chemotherapy and survival in $24^{*}$ patients with $C M L$

Survival duration (Months)

\begin{tabular}{lllll}
\hline Therapy & No. & Mean \pm s.d & Median & Range \\
\hline Alpha interferon & 6 & $62.8 \pm 20.3$ & 65 & $33-84$ \\
Hydroxyurea & 8 & $52.9 \pm 24.9$ & 47 & $25-86$ \\
Busulphan & 10 & $48.5 \pm 23.6$ & 39 & $24-88$ \\
\hline
\end{tabular}

*Overall survival duration for 24 patients was a mean \pm s.d. of $53.5 \pm 23.0$ months with a median of 52 months and range of 24 to 88 months 
The mean \pm s.d. for survival was higher in patients on alpha interferon therapy, compared to those on hydroxyurea and busulphan but the differences were not statistically significant between the three treatment schedules $(\mathrm{P}>0.05)$; (Table 4). An overall analysis of the 24 patients revealed a mean \pm s.d. survival duration of $53.5 \pm 23.0$ months with a median of 52 months (range 24 to 88 months). Patients tolerated chemotherapy well and were relatively free of toxicity except for "flu-like" illnesses for alpha-interferon; mucositis, nausea and diarrhoea for hydroxyurea and nausea, vomiting and headaches for those who were treated with busulphan. Subsequent follow-up of these 24 patients revealed that 12 died during the accelerated and blastic phases of the disease and two from bone marrow aplasia presumably as a sequel to busulphan overdosage. Of the remaining 10 patients, eight were lost to follow-up and only two were still alive at the time of this presentation.

\section{DISCUSSION}

The findings in the present study are in consonnance with the observations of many other investigators in subSaharan Africa as well as in the Western hemisphere and in people of the African diaspora (1-3, 6-10). The male predominance in this series has been documented by most (1-3, 6) but not all researchers (7). Although previous reports of increased incidence of CML during the first two decades of life in African children (8) were not confirmed in this study, the study reinforces previous findings that CML has a peak frequency between the 3rd and 4th decades of life as compared to the 5 th decade in the Western world; but this is most probably a reflection of the age structures of the populations (1-4).

The majority of patients $128(85.3 \%)$ presented in the chronic phase with symptoms attributable to severe or gross splenomegaly and marked anaemia which in turn could be attributed to late presentation, hyper-leucocytosis, endemic malaria and possibly increased hypersplenism. Other notable clinical findings which to date have been considered to be rare (7) included: hepatomegaly, bleeding, Iymphadenopathy, purpura, skin infiltration and visual disturbance. In their study, Thompson and Stainsby (7) described initial findings in 169 patients with CML, most of whom were diagnosed before 1970 .

In their series, only "occasional" patients were diagnosed incidentally and virtually all presented with splenomegaly. In contemporary practice, however, several authors largely from Western developed nations $(2,3,9,10)$ have suggested that patients with CML are often asymptomatic at diagnosis. Our present study has documented that an incidental diagnosis is made in about one of every seven patients with CML; a figure comparable with one of every five patients recently found at the Hammersmith Hospital, UK (4). About one out of eight patients lacked a palpable spleen. With current medical practice, it is likely that CML patients are now being diagnosed earlier for several reasons including greater awareness of the disease among clinicians, periodic routine medical evaluations with physical examination and laboratory testing and the introduction of technologically advanced Coulter counters that accurately estimate leucocyte, haemoglobin and platelet measurements which were not routinely done several decades ago.

Marked leucocytosis (Wbc $\geq 100 \times 10^{9} / \mathrm{L}$ ) was common but features of leucostasis such as retinopathy, priapism, mental and otological disturbance were unusual; just as other previous workers $(4,7)$ have noted. Furthermore, although thrombocytosis (Platelet count > $450 \times 10^{9} / \mathrm{L}$ ) was common, classic ischaemic vascular disease like stroke or myocardial infarction was not seen possibly due to the relative youth of the local population. Haemorrhagic manifestations which occurred in 18 (12\%) patients contrasted with the high incidence of bleeding in newly diagnosed CML patients in the Western study (7); and no correlation was found between platelet count and bleeding episodes. Furthermore, bleeding tendencies generally disappeared with treatment suggesting that platelet dysfunction commonly associated with CML was the most likely mechanism behind haemostatic failure. Another interesting finding in this study is that two patients were found to be pregnant at diagnosis and successfully delivered normal infants subsequently. This implies that untreated CML patients are fertile.

The two patients were treated with busulphan which had to be given because its use outweighed potential hazards and the patients were above the first trimester when busulphan teratogenic and embryotoxic effects are commonest (11). Pregnancy, relatively uncommon in CML, appears not to alter the disease (12). Its rarity may be related to the age of the patients at presentation including amenorrhoea, infertility and sterility due to busulphan therapy (11). Chemotherapy with alpha-interferon, hydroxyurea and busulphan merely ameliorated the signs and symptoms of the disease in the 24 patients who were treated as there were no cures. The mean \pm s.d. survival duration was higher in the alpha-interferon treated group compared to the hydroxyurea and busulphan groups but the differences between the three treatment schedules did not reach statistical significance $(\mathrm{P}>0.05)$. Some patients initially showed undue sensitivity to the drugs and some appeared to be less responsive requiring higher doses; especially patients with markedly raised leucocyte counts (Wbc $\geq 250 \times 10^{9} / \mathrm{L}$ ). Besides other factors, individual genetic factors, the degree of leucocyte count at presentation and $\mathrm{Ph}$ chromosome status may influence response to chemotherapy. Since the $\mathrm{Ph}$ chromosome is one of the factors that correlate with better prognosis (14), it merits special mention. Presently, to our knowledge, detailed cytogenetic studies in African CML patients are, unfortunately, extremely scanty. But it is possible that differences in cytogenetic patterns exists in African and Caucasian CML patients. This is probably one of the reasons why the response in treatment protocols as used in Caucasians is not so successful in indigenous Africans.

Another important factor, though not encountered in our patients, is the failure of the patients to take treatment 
as prescribed. Aken'ova and Campbell (13) recently reported a mean survival duration of 48.7 months with a median of 38 months and a range of 24 to 112 months in Nigerian CML patients on chemotherapy. In the 24 patients treated with chemotherapy in this study, the overall survival duration was 53 months with a median of 52 months and range of 24 to 88 months. However, further studies in large series including detailed molecular studies that indicate $\mathrm{Ph}$ chromosome positive variants viz: p 190 disease, p 210 disease and p 230 disease (15) need to be conducted in African CML patients to clarify the response to chemotherapy. Although, currently, it is impossible to cure CML with available chemotherapeutic agents, good palliation is far better than nothing at all. However, in Africa in general and in the two centres in particular where these studies were conducted, these agents are not readily available. It is therefore suggeted that International Patient Assistance Initiatives such as the GIPAP established by Norvatis Pharma AG in collaboration with Axios should equip African referral centres to enable CML patients managed at these centres have access to newer cancer life saving drugs such as Glivec which is currently advocated for Ph chromosome positive CML. It is only through such partnerships between pharmaceutical industry and African academic research institutions that CML patients in African countries with meagre resources will have any real hope of survival.

\section{ACKNOWLEDGEMENTS}

To the various colleagues under whom some of the patients included in this study were admitted and looked after. To Mrs. M.T. Bwanali, Secretary, Department of Haematology, College of Medicine, University of Malawi, for secretarial services and above all, to the Secretaries for Health, Ministries of Health, Zimbabwe and Malawi Governments, for permission to publish this manuscript.

\section{REFERENCES}

1. Fleming, A.F. A bibliography of the leukaemias in Africa 19041985. Leuk. Res. 1986; 10:1353-1365.

2. Goldman, J.M. Chronic myeloid leukaemia. In: Oxford textbook of medicine 3rd edn., (eds), D.J. Weatherall, J.G.G. Ledingham and D.A. Warrell.Oxford University Press, Oxford, UK. 1996;22:34153419.

3. Larson, R.S. and Wolff, S.N. Chronic myeloid leukaemia. In: Wintrobe's clinical haematology 9th edn. Vol.2, (eds), G.R. Lee, J.. Foerster, J.. Lukens et al., Lippincott Williams \& Wilkins, Philadelphia, PA. USA. 1993; 90:2342-2373.

4. Savage, D.G. Szydlo, R.M. and Goldman, J.M. Clinical features at diagnosis in 430 patients with chronic myeloid leukaemia seen at a referral centre over a 16 year period. Brit. J. Haematol. 1997; 96:111-116.

5. Dacie, J.V. and Lewis, S.M. Practical Haematology, 7th Edn; J. \& A. Churchill, Livingstone, London, 1991.

6. Hoffman, W.J. and Graver, L.F. Chronic myelogenous leukaemia: value of irradiation and its effect on the duration of life. J. Amer. Med. Assoc. 1931; 97:836-840.

7. Thompson, R.B and Stainsby, D. The clinical and haematological features of chronic granulocytic leukaemia in the chronic phase. In: Chronic granulocytic leukaemia, (ed.), M.T. Shaw. Praeger, Esst Sussex, UK. 1982; 137-167.

8. Lowe, R.F. Chronic myelocytic leukaemia in African Children. Trans. Roy. Soc. Trop. Med. Hyg. 1971; 65:840-841.

9. Hughes, T.P. and Goldman, J.M. Chronic myeloid leukaemia. In Haematology, Basic Principles and Practice 2nd edn., (ed.), R. Hoffman. Churchill Livingstone, New York, USA. 1995; 854-869.

10. Lichtman, M.A. Chronic myeloid leukaemia and related disorders. In: Williams Haematology 5th edn., (ed.), E. Beutler, M.A. Lichtman, B.S. Coller and T.J. Kipps. McGrawHill, New York, USA. 1995; 298-324.

11. Dollery, C. Therapeutic Drugs, 1st edn.; Churchill Livingstone, Edinburgh. 1992.

12. Johnson, F.D. Pregnancy and chronic myelogenous leukaemia. Amer. J. Obstet. Gynecol. 1972; 112:640-644.

13. Aken'ova, Y.A. and Campbell, O.B. The efficacy of chemotherapy and splenic irradiation in the management of chronic myelogenous leukaemia at Ibadan, Nigeria. Cent. Afr. J. Med. 1993;39:133-136.

14. Lawler, S.D. The Cytogenetics of chronic granulocytic leukaemia. Clin. Haematol. 1997; 6:55-75.

15. Goldman, J. M. Chronic myeloid Leukaemia. In: Leukaemia and related disorders 3rd edn., (eds), J.A. Whittaker and J.A. Holmes. Blackwell Science Ltd., Oxford, Uk. 1998; 13:252- 269. 